\title{
INTERSECCIONALIDADES EM TEXTO MULTIMODAL NO LIVRO DIDÁTICO DE LÍNGUA PORTUGUESA DO ENSINO FUNDAMENTAL
}

\section{INTERSECTIONALITIES IN MULTIMODAL TEXT IN THE PORTUGUESE LANGUAGE TEACHING BOOK OF FUNDAMENTAL EDUCATION}

\author{
Ana Márcia R. de Miranda Macedo* \\ Rubenilson Pereira de Araujo
}

\begin{abstract}
Resumo: A interseccionalidade é o conjunto aditivo que potencializa as discriminações e torna-se o mecanismo que diferencia as experiências de opressão e de privilégios. Diante disso, o objetivo da pesquisa consistiu em analisar o processo de inclusão das temáticas que denotam estereótipos em relação às diferenças de identidades e suas interseccionalidades, priorizando um texto multimodal no livro didático de Língua Portuguesa, do Ensino Fundamental, distribuído pelo Programa Nacional do Livro Didático (PNLD, 2013). Como base teórica temos (BRASIL, 2017), (BNCC, 2017), (CRENSHAW apud PISCITELLI, 2008), (Diretrizes Nacionais Curriculares, 2013), (MOITA LOPES, 2002), (SILVA, 2009) e (WOODWARD, 2009). Como subsídio metodológico, utilizamos a pesquisa bibliográfico-documental. Para isso, a análise centrou-se nas atividades da coleção do livro didático (LD) Português: Linguagens, Ensino Fundamental (CEREJA; MAGALHÃES, 2015), priorizando as imagens e, em alguns casos, as atividades de leitura (compreensão e interpretação de textos). A escolha das atividades/imagem analisadas ocorreu de acordo com a temática interseccional sobre a mulher, o idoso e as diferenças no livro didático de Língua Portuguesa que preconizam os estigmas socioculturais na coleção. Fez-se leitura da coleção e, posteriormente, a atividade selecionada foi a que mais nos chamou atenção
\end{abstract}

\footnotetext{
"Mestre em Linguística Aplicada pela UFT- Universidade Federal do Tocantins, Campus de Porto Nacional TO (2018), professora efetiva da Secretaria da Educação do Estado do Tocantins (2010) e graduada pelo Ceulp/Ulbra-Centro Universitário Luterano de Palmas Tocantins (2005).Email: ana_marcia85@hotmail.com.

"'Doutor em Letras: Ensino de Língua e Literatura pelo Programa de Pós Graduação em Letras da Universidade Federal do Tocantins/UFT, onde atua na graduação e pós- graduação em Letras, desenvolvendo pesquisas sobre gênero, diversidade sexual, educação linguística e literária na Formação Inicial e Continuada de Professores da Educação Básica. Atualmente, está na coordenação do curso de graduação em Letras e na cadeira de Prática de Ensino e Estágio Supervisionado em Língua e Literatura, campus Porto Nacional. Email: rubenilsonpereira@gmail.com.
} 
no $\mathrm{LD}$, descrevendo e analisando qual o tipo de preconceito predominante e questões subjacentes. Essa coleção foi escolhida devido a ter sido destaque na exigência de leitura, de acordo com os cálculos do MEC em 2005 e 2008. O resultado obtido é que, embora haja alguns estudos sobre as diferenças de identidades, ainda não há afirmação dessas diferenças por parte da coleção do livro didático analisado. Com isso, verificamos que a abordagem é apresentada de forma breve, principalmente sobre a intersecção dos estereótipos que sobrepõem. Por isso, são necessárias ações pedagógicas planejadas intencionalmente e políticas públicas educacionais por parte do Estado e dos professores, considerando as representações do "diferente" nas instituições escolares.

PalaVRas-Chave: Instituição Escolar; Preconceito; Diferença; Intersecção.

AвSTRACT: Intersectionality is the addictive set that enhances discrimination and becomes the mechanism that differentiates experiences of oppression and privileges. Therefore, the objective of the research was to analyze the inclusion process of the themes that denote stereotypes in relation to the differences of identities and their intersectionalities, prioritizing a multimodal text in the Portuguese Language textbook, of Elementary Education, distributed by the National Book Program Didactic (PNLD, 2013). As theoretical basis we have (BRASIL, 2017), (BNCC, 2017), (CRENSHAW apud PISCITELLI, 2008), (National Curricular Guidelines, 2013), (MOITA LOPES, 2002), (SILVA, 2009) and (WOODWARD, 2009). As a methodological subsidy, we used bibliographic and documentary research. For this, the analysis focused on the activities of the Portuguese textbook (LD) collection: Languages, Elementary Education (CEREJA; MAGALHÃES, 2015), prioritizing images and, in some cases, reading activities (comprehension and interpretation of texts). The choice of the analyzed activities / image took place according to the intersectional theme about women, the elderly and the differences in the Portuguese language textbook that advocate the socio-cultural stigmas in the collection. The collection was read and, subsequently, the selected activity was the one that most caught our attention in the $\mathrm{LD}$, describing and analyzing the prevailing type of prejudice and underlying issues. This collection was chosen because it was highlighted in the reading requirement, according to MEC calculations in 2005 and 2008 . The result obtained is that, although there are some studies on the differences in identities, there is still no affirmation of these differences on the part of the analyzed textbook collection. With that, we verified that the approach is presented in a brief way, mainly about the intersection of the overlapping stereotypes. For this reason, intentionally planned pedagogical actions and educational public policies are needed by the State and teachers, considering the representations of the "different" in school institutions.

KEYwords: School Institution; Preconception; Difference; Intersection. 


\section{INTRODUÇÃo}

O livro didático é o principal material utilizado pelos educadores em sala de aula, senão, em muitos casos, o único, que orienta as práticas pedagógicas de forma sistemática e sua difusão no trabalho docente. Desse modo, o contato com o livro e com suas informações é de real importância para a construção de valores, de conhecimentos e de informações. Historicamente, com o domínio em toda educação básica, o livro didático é um instrumento de letramento que contribui para o exercício da cidadania no Brasil, no sentido de desenvolvimento da qualidade, e é distribuído a estudantes de escolas públicas, gratuitamente, pelo Programa Nacional do Livro Didático (PNLD).

Muitas têm sido as pesquisas desenvolvidas sobre o livro didático no Brasil por estudiosos/as e por formuladores de políticas públicas, com o objetivo de melhorar a educação e a qualidade do ensino, por meio do PNLD. Dentre essas pesquisas, destacamos as temáticas a respeito das influências ideológicas das imagens no livro que contemple a diversidade social e cultural de Souza (2014); Literaturas afro-brasileira e africana e o desafio nos livros didáticos de língua portuguesa para o ensino médio de Costa (2014) e Discursos sobre relações raciais em livros didáticos de português para as séries iniciais do Ensino Fundamental de autoria de Júnia (2010), que vêm contribuindo para o rompimento de preconceito de raça, de cor, de gênero e religião.

De acordo com Rojo e Batista (2003), muitas coleções já têm sido aperfeiçoadas em atender os diferentes interesses, gerados pelos fatores de ordem regional, cultural e social. Essa concepção do livro didático flexível destina-se à parte diversificada das formas de organização escolar e dos projetos político-pedagógicos, com base na diversidade das necessidades e nos interesses sociais e regionais. Tais mudanças têm ocorrido desde 1985, quando foi definido o Decreto-Lei n. ${ }^{\circ}$ 91.542, que estabeleceu e fixou parte das características atuais do PNLD, dentre elas, a escolha do livro didático por professores/as, a sua distribuição gratuita às escolas e a sua aquisição com recursos do Governo Federal.

Como principal recurso usado em sala de aula, o livro precisa trazer conceitos fundamentais nas diversas disciplinas do saber, de forma bem estruturada, em uma linguagem de fácil entendimento, simplificada para facilitar a obtenção de conhecimentos pelos/as alunos/ as. No entanto, estudos e investigações sobre as produções didáticas brasileiras vêm denunciando a falta de qualidade.

Assim sendo, abordamos as interseccionalidades sobre os diversos tipos de estereótipos contidos no livro didático que articulam as diferenças sociais, raciais e de identidade. Pensando nisso, os educadores precisam de fundamentos para abordagem de leitura, das imagens e de produção de texto, a fim de que não se tornem meros reprodutores da política vigente na escolha do livro didático, visto que, nos livros de Língua Portuguesa, como nos de outras áreas, existem textos, imagens caricaturais, fotos que retratam desigualdades, diversidades, aspectos socioculturais, históricos e diferenças de identidades. 
O embasamento teórico centra-se nas teorias de (BRASIL, 2017), (BNCC, 2017), (CRENSHAW apud PISCITELLI, 2008), (DNC, 2013), (MOITA LOPES, 2002), (SILVA, 2009) e (WOODWARD, 2009), os quais discutem sobre as temáticas envolvidas como diferenças de identidades, intersecção de preconceitos e direitos das mulheres e idosos.

O corpus da pesquisa constituiu-se da coleção do LD Português: Linguagens, de William Roberto Cereja e Thereza Cochar Magalhães, publicada pela editora Saraiva. A opção pela referida coleção se deve ao fato de ela existir desde 1998, abrangendo do $1 .^{\circ}$ ao $9 .^{\circ}$ ano e todo Ensino Médio. É importante ressaltar que essa coleção é adotada pela maioria das escolas brasileiras, segundo o Guia do Livro Didático.

O presente artigo está dividido em três partes. Na primeira, na discussão teórica, abordamos a respeito de identidades, diversidade e questões interseccionais, na segunda parte analisamos o texto multimodal "A construção sociocultural da anormalidade de outrem: a faixa etária e suas diferenças" e na última fizemos as considerações finais.

\section{Discussão TEÓRICA}

IDENTIDADE, DIVERSIDADE E QUESTÕES INTERSECCIONAIS

Nos dias atuais, muito se tem discutido sobre questões de identidade, devido às diferenças sociais, raciais, sexuais e de gêneros, com o objetivo de desfazer a predominância da hegemonia única: o branco, o heterossexual masculino. As lutas sociopolíticas com direito ao mosaico têm sido o grande interesse das Ciências Humanas, que procuram compreender o ser humano. Não está sendo uma tarefa fácil, apesar das pesquisas que procuram analisar os aspectos psicológicos, cognitivos e sociais do sujeito. (MOITA LOPES, 2002). Essa dificuldade, muitas vezes, deve-se ao fato de considerarmos um mundo plural, onde é respeitada a experiência humana de forma homogênea, quando deveríamos levar em conta a heterogeneidade típica de um povo.

Nesse sentido, observamos que a identidade de um povo está relacionada à diferença e à idiossincrasia que existe em cada ser humano: a maneira de agir, de pensar, de ser depende de cada indivíduo, pois, de acordo com Silva (2000), em um primeiro momento, parece fácil definir identidade como aquilo que se é: "sou brasileiro", "sou negro", "sou heterossexual", "sou jovem", "sou homem". Assim, a identidade parece ser vista como algo positivo, sendo, portanto, uma característica independente. A diferença, segundo o referido autor, também é concebida como entidade independente, porém em oposição à identidade. Em outras palavras, a diferença é aquilo que o outro é: "ela é italiana", "ela é branca", "ela é homossexual", "ela é idosa”, "ela é mulher". Nesse caso, a diferença é vista como algo que remete a si próprio e não a todos. No entanto, identidade e diferença estão em uma relação de estreita dependência. 
Diante desse contexto, observa-se a complexidade do termo identidade e o estudo sobre o assunto, já que o ser social, muitas vezes, acha que suas características, seus meios simbólicos, são promissores, melhores que os do outro e não olha para o seu eu. Outro ponto que merece destaque são as mudanças de identidades pelas quais passamos no decorrer de nossa existência, e isso se deve a vários fatores, como

[...] as mudanças rápidas que as sociedades têm enfrentado ultimamente - tais como a locomoção/imigração de um continente a outro, em curto espaço de tempo, e a comunicação via meio eletrônicos, em tempo real - têm tornado mais e mais aparente a existência de confronto identitários ao mesmo tempo em que possibilitam o processo de exposição a outras identidades e, portanto, de recomposição de quem somos diante dos outros, inclusive por meio de identidades virtuais. (TURKLE apud MOITA LOPES, 2002, p. 58).

$\mathrm{Na}$ fase de construção dessas identidades diversas do ser humano, a escola deve ser promotora de socialização, ou seja, deve construir o elo de esclarecimento entre alunos e professores, preparando os discentes para exposição nas práticas discursivas fora do contexto escolar, pois é na escola que, inicialmente, a criança começa a se expor publicamente. Por isso, é fundamental que discussões sejam realizadas, a fim de esclarecer que a identidade não é fixa e imutável.

Sabemos que a identidade cultural de um povo não é um produto acabado; constitui-se, antes, em um processo em construção. Seus elementos são compostos de bens culturais comuns a uma sociedade: língua, história, costumes, idade, religião. Há uma representação quando falamos, quando agimos. Nesse sentido, mostramos as nossas diferenças. O sujeito sempre fala a partir de uma posição histórica específica, em relação ao seu passado (WOODWARD, 2009). Assim, a construção da identidade é tanto simbólica como social. A nossa identidade nacional é marcada pelo gênero masculino; por isso, nossas ações estão ligadas à concepção militarista de masculinidade. Podemos afirmar, a partir disso, que o termo masculino sempre teve mais força, enquanto o feminino é visto como algo frágil, que não pode enfrentar uma guerra entre países, por exemplo.

Afirmamos que é simbólica por analisar algo que identifica um grupo específico e não outro. Um exemplo disso, conforme Woodward (2009), são as características de uma determinada cultura: gosto pelo rock como música, não tem religião, gostos por bebidas alcoólicas. Já outras culturas, como a negra, gostam de seguir uma religião, gostam de dançar, fazer rituais etc. O social está ligado à identidade simbólica, pois "a marcação simbólica é o meio pelo qual damos sentido às práticas e a relações sociais, definindo, por exemplo, quem é excluído e quem é incluído" (WOODWARD, 2009, p. 14). É por meio da diferenciação social que acontecem as diferenças que são vividas nas relações sociais e que podem ser divididas entre "nós" e "eles". 
Atualmente, há uma preocupação com a identidade no sentido global, principalmente quando pensamos em diversidade, com as identidades pessoais, nacionais, políticas, sexuais e étnicas. Há vários teóricos que definem o termo, porém percebemos que a maioria direciona para a mesma definição. Identidade diz respeito à diversidade que vivemos hoje, à luta pelo reconhecimento das contingentes verdades, pois sabemos que nada é definitivo. Existem múltiplas verdades, e não apenas uma absoluta. Identidade depende também do momento e da situação em que o sujeito se encontra, visto que somos "várias pessoas" em uma só, desempenhamos várias funções e representamos vários papéis no dia a dia. Identidade é a produção de significados construídos nos diversos saberes: cultura, história e nos discursos que são ressignificados, a partir dos quais os sujeitos se posicionam quando podem falar.

O termo interseccionalidade, ou teoria interseccional, refere-se ao estudo da sobreposição ou da intersecção de diferentes formas de subordinação/opressão. A teoria remete a diferentes categorias de opressão, de dominação ou de discriminação, em relação às identidades sociais divergentes, tais como diferenças sociais, culturais, de gênero, de raça, de religião, de capacidade, de orientação sexual etc.:

[...] as interseccionalidades são formas de capturar as consequências da interação entre duas ou mais formas de subordinação: sexismo, racismo, patriarcalismo. Essa noção de 'interação' entre formas de subordinação possibilitaria superar a noção de superposição de opressões. Por exemplo, a ideia de que uma mulher negra é duplamente oprimida, à opressão por ser mulher deve ser adicionada a opressão por ser negra. (CRENSHAW apud PISCITELLI, 2008, p. 267).

A interseccionalidade mostra a existência de injustiça, de desrespeito em diversas abordagens dentro da sociedade. Ou seja, o preconceito, os estereótipos, os estigmas acontecem de forma simultânea nos diversos eixos de identidade. Como o exemplo acima, percebemos que a mulher sofre opressão pelo fato de ser mulher e de ser negra (cor da pele e raça enquadrada), assim como existe homofobia e preconceito racial se um homem assumir a orientação homossexual e pertencer à raça negra.

Outro exemplo a que recorremos é o fato de uma pessoa de terceira idade ser discriminada pela idade e pelo fato da condição de ser mulher. Notamos, assim, que as formas de intersecção se inter-relacionam, tornando-se dependentes uma da outra, formando diversas formas de discriminação e de preconceitos.

Quando falamos de gênero feminino, lembramos várias categorias de estigmas que se referem a ele e que se interseccionam, decorridas de violência, de menores salários, de preconceitos contra a cor, a classe social. Esses elementos estão em evidência por causa de lutas contra os dissabores que a classe feminina vem passando na trajetória de vida. A luta entre as diferenças de homens e de mulheres tem crescido, em busca constante de legitimar os direitos femininos por meio do movimento feminista. 
Feminismo é um movimento organizado pelas mulheres, no ocidente moderno, que propõe igualdade nas relações delas com os homens, mediante mudança de valores, de comportamentos e de atitudes, em todas as esferas da vida humana. (ALBERNAZ; LONGUI, 2009, p. 76).

Dessa forma, entende-se que o feminismo tem a finalidade de lutar pela igualdade de direitos, no entanto muitas pessoas não concordam com isso. Esses casos estão relacionados aos aspectos religiosos, culturais, que veem a mulher como ser submisso. Crenshaw (2002) discute sobre as intersecções de raça e de gênero em relação às mulheres e afirma que os direitos humanos são direitos das mulheres e que os direitos das mulheres são direitos humanos. Em outras palavras, quando os direitos humanos das mulheres eram violados, semelhantes aos direitos dos homens, elas não eram protegidas, porque esses problemas estão ligados às questões de gênero e, como consequência disso, de acordo com Crenshaw, após as conferências de Viena (1992) e de Pequim (1995), as mulheres passam a entender que "os direitos das mulheres são direitos humanos" e devem ser protegidos.

Embora com avanços, depois de lutas constantes, a mulher ainda vive em opressões irredutíveis pela sociedade que a julga e a vê como um ser refém do colonialismo e do patriarcalismo, representado pelo ser masculino, por meio de múltiplas dominações. Podemos pensar nas intersecções de gênero com modalidades de raça, sexual, de classe de que a mulher é vítima, perfazendo assim a falta de reconhecimento de uma classe humana que luta pela melhoria de vida. Há também outros tipos de discriminação da mulher em função da deficiência, da idade etc. Afirmamos isso quando a mulher deixa de ser empregada em uma determinada empresa por causa da idade avançada, considerada como não agente, incapaz de exercer uma profissão.

O envelhecimento humano é uma área de estudo, principalmente da saúde, que tem crescido e se expandido cada vez mais, porém é fundamental percebermos que a longevidade não é igual para todos e as diferenças existentes dependem de condições de atendimento social, acesso aos bens de serviços, além de cobertura de rede de proteção. Embora protegidos pelo Estatuto do Idoso, muitos idosos sofrem por a sociedade não assegurar seus direitos, com o objetivo de melhorar a qualidade de vida da terceira idade.

Art. $3^{\circ}$ - É obrigação da família, da comunidade, da sociedade e do Poder Público assegurar ao idoso, com absoluta prioridade, a efetivação do direito à vida, à saúde, à alimentação, à educação, à cultura, ao esporte, ao lazer, ao trabalho, à cidadania, à liberdade, à dignidade, ao respeito e à convivência familiar e comunitária. (BRASIL, 2017, p. 8).

Atingir um envelhecimento ativo é um objetivo de vida para todos. Para que isso ocorra, é necessário que a sociedade pense e planeje melhores condições de vida, visando a uma velhice frequente nos espaços públicos de convivências que abrangem o chamado grupo de terceira 
idade, como espaços religiosos, culturais, centros de saúde públicos ou privados, incluindo assim a heterogeneidade como sinal do processo de envelhecimento que caracteriza a vida das pessoas.

A fase da velhice é vista por alguns como decadente, inútil, exclusão e morte, principalmente pelos jovens, que ainda não possuem maturidade. Esses elementos negativos tratam de preconceitos que rotulam e, assim, dificultam políticas públicas para a inserção do idoso na sociedade. Além disso, acreditamos que as mulheres idosas sofrem ainda mais pelo fato de serem do gênero feminino, principalmente se considerarmos a violência contra a mulher. Para coibir isso, temos como principal referência a Lei Maria da Penha (Lei 11.340/2006), a qual objetiva prevenir e coibir a violência contra a mulher.

\section{ANÁlise Do TEXTo MULTIMODAL}

A CONSTRUÇão SOCIOCULTURAL DA ANORMALIDADE DE OUTREM: A FAIXA ETÁRIA E SUAS DIFERENÇAS

Na Unidade 03, no Capítulo o1 do LD do 7. ${ }^{\circ}$ ano, temos o texto Bruxas não existem, de Moacyr Scliar. O capítulo inicia com alguns questionamentos, como: "Às vezes, podemos estranhar e até não compreender as pessoas que vivem à nossa volta. Mas será que temos direito de não aceitá-las? Temos o direito de ser cruéis com o outro somente porque ele é diferente de nós?”. (CEREJA; MAGALHÃES, 2015, p. 138).

O texto referido fala de um menino que chama a vizinha de bruxa, juntamente com seus coleguinhas, devido à senhora ter características físicas diferentes, gorda, enorme, cabelos que pareciam palhas, nariz comprido etc. No entanto, em um determinado dia, o menino sofre um acidente e a senhora, então considerada bruxa, o salva e o leva para a mãe cuidar dele. A partir disso, o garoto se torna amigo da senhora, que era muito boa.

O que se observa diante da imagem e das atividades é que não há reflexão sobre os idosos e seus direitos. O texto mostra apenas a atitude bondosa da senhora e a reação contrária dos adolescentes, mostrando como as pessoas da terceira idade ${ }^{1}$ são tratadas, principalmente pelos jovens, que os veem como pessoas insignificantes. Para compreender melhor, há vários tipos de violência: violência contra a mulher, violência doméstica e violência contra o idoso (estabelecida pela Lei $n .^{\circ}$ 10.741/2003). Nesse caso, priorizamos a violência contra o idoso, relacionando a intersecção da violência contra a mulher.

\footnotetext{
${ }^{1}$ A palavra terceira idade, atualmente tão usada, teve sua origem na França, na década de 1960, e era utilizada para descrever a idade em que a pessoa se aposentava. A primeira idade seria a infância, que traduziria uma ideia de improdutividade, mas com possibilidade de crescimento. Já a segunda idade seria a vida adulta, etapa produtiva. Na época em que a expressão terceira idade foi criada, procurou-se garantir a atividade das pessoas depois da aposentadoria, que ocorria na França por volta dos 45 anos. Com o avanço contínuo da esperança de vida, a expressão "terceira idade" passou a designar a faixa etária intermediária entre a vida adulta e a velhice (NERI; FREIRE, 2000).
} 
Figura 01: Imagem de uma senhora considerada bruxa pelos adolescentes.

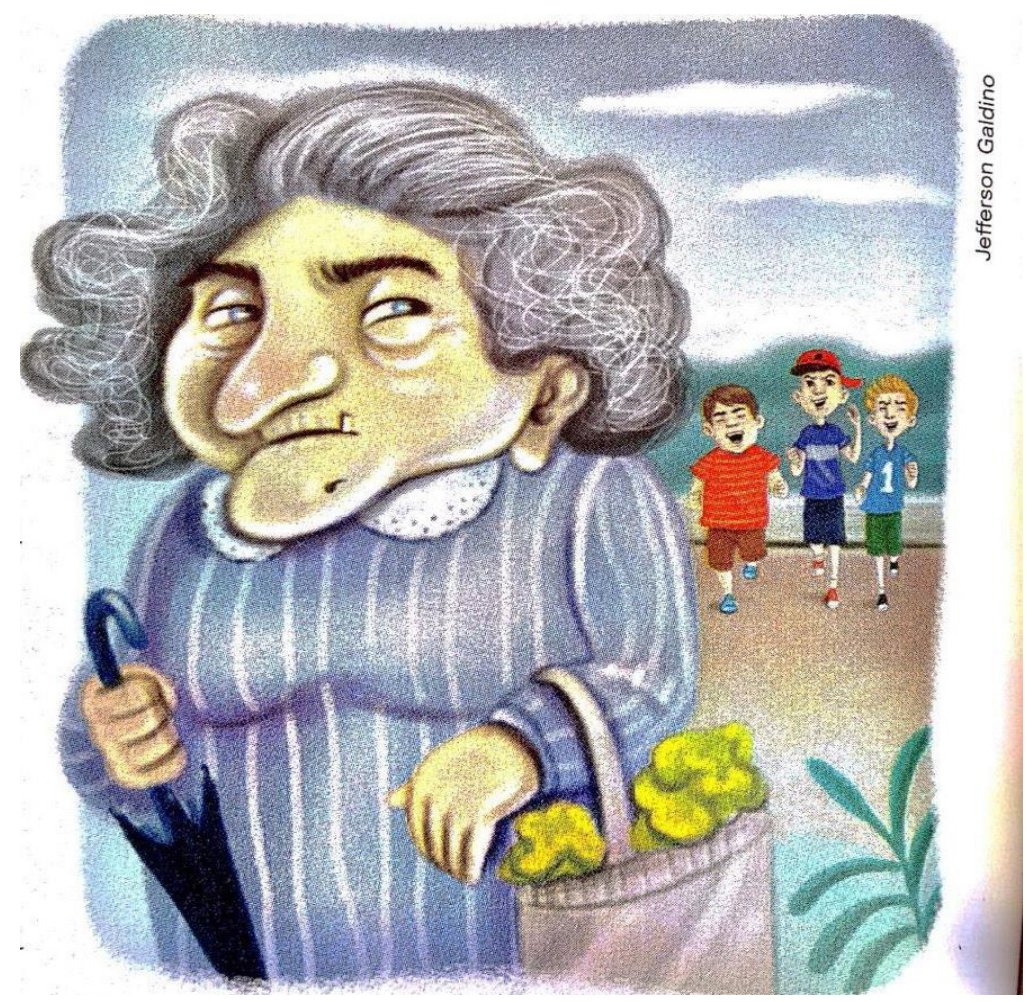

Fonte: Cereja e Magalhães (2015, p. 138).

Segundo Cordeiro e Scott (2009), pela força dos movimentos de mulheres, a Violência Contra as Mulheres possui uma conceitualização e os termos para caracterizá-la constituem uma sinalização política dos questionamentos e das ações e reações que ocorrem em torno dela, visto que existem a Violência Doméstica e Intrafamiliar. Pode ocorrer também, segundo os autores, que a violência seja evocada por mais de um tipo de violência. Essas formas de subordinação e de opressão se sobrepõem e se interseccionam, pois, no caso estudado da senhora considerada bruxa, mostra-se características que os movimentos sociais também lutam para combater: o fato de ser mulher e, ainda, de ser de terceira idade. Esses elementos, vistos pela sociedade como falta de capacidade, deixam as relações de gênero no âmbito das desigualdades, na posição entre homens e mulheres.

Vale destacar que a violência contra o idoso não acontece somente com as mulheres, porém é mais propícia nesse gênero devido a ser considerado por muitos "o sexo frágil". Dito isso, junta a velhice para diminuir o valor do ser humano como alguém que não seja capaz de fazer qualquer atividade. Esses fatores estão relacionados com o gênero, a cultura, a classe social, os padrões de vida individual e coletiva da sociedade. 
No Brasil, de acordo com o Estatuto do Idoso (2003), as pessoas com idade igual ou superior a 60 anos são reconhecidas como idosas, mas nem por isso são vistas como alguém inativo. No entanto, essas questões dependem da vida pessoal, familiar e profissional, que servem de pontos de referência para mudanças. $\mathrm{O}$ artigo 20 do Estatuto do idoso afirma que "O idoso tem direito a educação, cultura, esporte, lazer, diversões, espetáculos, produtos e serviços que respeitem sua peculiar condição de idade" (BRASIL, 2017, p. 14) e, mais adiante, no Artigo 21,

O Poder Público criará oportunidades de acesso do idoso à educação, adequando currículos, metodologias e material didático aos programas educacionais a ele destinados.

$\$ 1$.o Os cursos especiais para idosos incluirão conteúdo relativo às técnicas de comunicação, computação e demais avanços tecnológicos, para sua integração à vida moderna.

\$2.0 Os idosos participarão das comemorações de caráter cívico ou cultural, para transmissão de conhecimentos e vivências às demais gerações, no sentido da preservação da memória e da identidade culturais. (BRASIL, 2017, p. 14).

Dentro dessa perspectiva, a velhice passa a ser considerada uma fase boa da vida, não vista apenas pelas perdas, porém reconhecida pelos ganhos e pela administração das transformações, cabendo ao idoso potencializar as próprias capacidades e atuar nas vivências a que melhor se adaptem. Segundo Houaiss (2001), a palavra bruxa deriva do latim, de origem pré-romana, pelo castelhano bruja, "feiticeira". Ademais a palavra "bruxa" no idioma sânscrito (a língua sagrada da Índia) significa "mulher sábia”. Em latim, a palavra também significa larva de borboleta. Somando os significados podemos desconstruir o senso comum e afirmar que ser bruxa é ter a sabedoria e o poder de se auto transformar.

A LDB também dá visibilidade ao idoso quando afirma, no Artigo 37, que "A educação de Jovens e Adultos será destinada àqueles que não tiveram acesso ou continuidade de estudos no ensino fundamental e médio na idade própria” (p. 30).

Como o Brasil não é mais um país de jovens, mas um país que tem envelhecido, com mais de 15 milhões de pessoas com 60 anos ou mais, de acordo com o IBGE (2011), estima-se que a maior valorização do idoso possa acontecer em um futuro próximo, no qual o principal objetivo seria analisar os estereótipos relacionados à velhice. Assim, a visão do envelhecimento como sinônimo de última etapa da vida e perdas mudaria para a concepção de que essa fase do ciclo vital é um momento oportuno para novas conquistas e para a continuidade do desenvolvimento humano e dos saberes acumulados ao longo da vida e das experiências produzidas até então. Dessa forma, a sociedade teria ganhos que seriam utilizados a favor do indivíduo, dos que ainda estão em fase de crescimento e de aprendizado. 
Na Análise do Discurso, doravante AD, percebemos, nestes discursos, que o indivíduo, por meio da linguagem, seja escrita ou oral, exige uma forma de dizer. Se percebermos nossos atos de fala e escrita, veremos que, para cada contexto, se faz uso de uma estratégia diferente. Dessa forma, considerando a $\mathrm{AD}$ foucaultiana, observa-se o que está implícito nos questionamentos levantados pelo garoto em relação à senhora, pois o sentido, na $\mathrm{AD}$, não existe em si, porém é determinado pelos processos ideológicos inseridos nas questões sócio-históricas do sujeito e no contexto em que as palavras são produzidas.

Além disso, na $\mathrm{AD}$, devemos dar importância ao não-dito, pois o não-dizer pressupõe a existência de uma forma discursiva. "Sabe-se bem que não se tem o direito de dizer tudo, que não se pode falar de tudo em qualquer circunstância, que qualquer um, enfim, não pode falar de qualquer coisa". (FOUCAULT, 1996, p. 09).

No exemplo acima, notamos o não-dizer, no entanto o preconceito se reproduz no discurso do menino que não aceita a diferença da mulher, ligada à velhice, e isso se torna um fator negativo no pensamento do jovem moderno, além de relacionar a terceira idade com incapacidade, doença, improdutividade, características consideradas negativas nos valores sociais atuais. Diferença que é marcada por sua identidade que mostra a versão estereotipada de "bruxa".

As identidades são fabricadas por meio da marcação da diferença. Essa marcação da diferença ocorre tanto por meio de sistemas simbólicos de representação quanto por meio de formas de exclusão social. A identidade, pois, não é o oposto da diferença: a identidade depende da diferença. (WOODWARD, 2009, p. 40).

A diferença do outro é aquilo que eu não sou, pois a identidade se mostra como a representação do próprio "eu" da subjetividade; ela é representada a partir da linguagem, de aspectos históricos e culturais em que está inserido o sujeito. O "eu" considerado o "nosso" grupo, que constitui o menino, e o "outro", o grupo do "diferente", designado pela mulher (ROCHA, 1988), caracterizando assim o etnocentrismo. Isso vai ao encontro do que afirma Silva (2009): "A diferença é como a identidade, simplesmente, existe" (p. 74).

O narrador do texto "Bruxas não existem" conta que, quando era garoto, acreditava em bruxas. a) Como ele achava que eram as bruxas? b) Essa ideia do narrador era compartilhada por seus amigos?" (CEREJA; MAGALHÃES, 2015, p. 139). No entanto, no tópico estudado, não há referências às discussões sobre diferença de identidade, com exceção da última questão.

O texto lido aborda vários temas, entre os quais a maldade infantil, a solidariedade, a solidão, o julgamento baseado nas aparências. Que reflexões ele provoca quanto ao relacionamento que normalmente temos com o outro? (CEREJA; MAGALHÃES, 2015, p. 140). 
Nessa perspectiva, a identidade é livre e autossuficiente, capaz de ter várias versões de vida, isto é, várias formas de viver, sem a preocupação com o olhar do outro que muitas vezes o julga, como se pudéssemos ter somente uma identidade fixa, mas a identidade é uma “característica independente, um fato 'autônomo”. (SILVA, 2009, p. 74).

Entendemos o processo educacional como espaço crítico de formação da cidadania, na perspectiva de construção de uma sociedade mais solidária, democrática e igualitária. Conforme as Diretrizes Curriculares Nacionais para a Educação Básica (2013), o currículo deve ser construído com a finalidade de dar voz a diferentes grupos, como negros, indígenas, mulheres, crianças e adolescentes, homossexuais, pessoas com deficiência, interagindo com os estudos interseccionais dessas pessoas.

A escola, juntamente com o currículo, precisa romper paradigmas tradicionais fragmentários das áreas, conforme citam Moraes (1997) e Fiorin (2008), e fomentar o caráter interdisciplinar, na busca de integração no currículo, por meio das diversas áreas do conhecimento, a fim de tornar os conhecimentos abordados mais significativos para os educandos, promovendo a participação contínua de alunos com interesses, habilidades e experiências de vida muito diferentes.

À medida que os estudantes se conscientizarem das leis e dos estatutos que defendem os direitos dos idosos, das mulheres, dos negros, dos homossexuais, dos indígenas, a opinião e os estereótipos devem diminuir. É necessário que o currículo escolar tire do papel e coloque em prática essas questões e mostre que as diferenças existem e que o acesso à educação é um direito de todos, ao contrário da dominação, que historicamente tem privado do direito de aprender. Por isso, a Linguística Aplicada defende a alteridade, o respeito mútuo às diferenças e a diversidade na educação, para que se efetive a possibilidade de todos participarem de uma sociedade livre e democrática.

\section{CONSIDERAÇõES FINAIS}

O resultado das análises nos permitiu observar que o preconceito ainda é latente e o respeito às diferenças identitárias e às diversidades ainda permanecem. No livro didático analisado, mesmo com a publicação de documentos oficiais, como a DNC (2013) e a BNCC (2017), que defendem uma prática social voltada para a vida sociocultural do estudante, observamos os que julgam, sem considerar as diferenças existentes entre as pessoas.

Pensando por essa perspectiva e por estudos feitos, no que se refere à intersecção de estereótipos veiculados no LD, percebemos que ainda existem formas de discriminação por meio dos textos multimodais presentes no livro. Dessa forma, a coleção analisada trabalha, em parte, de maneira preconceituosa. Isso ficou presente na imagem da idosa e dos adolescentes contidas no LD. 
Acreditamos que esses fatores se devem principalmente à política nacional do livro didático, vista como um subcampo que pertence à educação, restrita à sistematização estatal que se estrutura por meio das ações e de seus agentes que dominam a concentração de capital. Assim sendo, não reproduzem nem legitimam a voz dos excluídos socialmente, deixando de cumprir o que dispõem as leis vigentes.

É imprescindível que os debates sobre as diferenças de identidades e as diversidades façam parte das aulas de língua com outras disciplinas do saber. A escola deve ser espaço de discursos que estão nos âmbitos sociais e nas práticas cotidianas. Não podemos nos calar diante das ideologias que a sociedade impõe como o certo, como o padrão e esquecer a diversidade de culturas, das diferenças entre jovens e idosos, da identidade de gênero, que nos faz calar por ser um assunto "tabu" e imposto pelo Estado, como detentor do poder.

Entendemos ainda que o reconhecimento, em parte, dos grupos minoritários, tem sido feito a partir de movimentos sociais, os quais buscam a igualdade de direitos. Um exemplo disso são as modificações ocorridas nos documentos oficiais ao longo das últimas décadas, na tentativa de inserir os estudantes na realidade local de cada um e, com isso, desenvolver uma visão crítica das disciplinas cursadas e uma visão global do mundo moderno, através de luta no campo jurídico, por intermédio de leis que defendem seus direitos, rompendo com a identidade hegemônica dominante, que é contestada em meio a uma pluralidade de identidades em evolução.

Finalmente, acreditamos que este trabalho possa trazer mais discussões sobre a temática de intersecção de preconceitos que tanto diminui as vítimas de etnocentrismo, e trazer a realidade como realmente acontece nas instituições escolares. Além disso, entendemos que nossa pesquisa tem valor coletivo e educacional ao trazer a realidade implícita que, muitas vezes, não enxergamos nas entrelinhas contidas no livro didático. Por isso, imaginamos que essa temática deve ser aprofundada, a fim de que tenhamos subsídio para trabalhar por uma política educacional progressista e diversificada.

\section{REFERÊNCIAS}

ALBERNAZ, L. S.; LONGHI, M. Para compreender gênero: uma ponte para relações igualitárias entre homens e mulheres. In: SCOTT, P.; LEWIS, L.; QUADROS, M. T. de (Orgs.). Gênero, diversidade e desigualdades na Educação: interpretaçõese reflexões para a formação docente. Recife: Editora Universitária UFPE, 2009, p. 75-95.

BRASIL. Estatuto do Idoso: Lei n.010.741, de 1 de outubro de 2003. Dispõe sobre o estatuto do idoso e dá outras providências. Brasília: Senado Federal, 2003.

BRASIL. Ministério da Educação. CNE/CEB. Diretrizes Curriculares Nacionais para a Educação Fundamental Brasília, 2013. 
BRASIL. Ministério da Educação. Base Nacional Comum Curricular - BNCC Ensino Fundamental. Brasília, DF, 2017.

BRASIL. Lei Maria da Penha. Lei n. 11.340/2006 Coíbe a violência doméstica e familiar contra a mulher. Presidência da República, 2006.

BRASIL. Ministério da Educação. CNE/CEB. Diretrizes Curriculares Nacionais para a Educação Fundamental Brasília, 2013.

BRASIL Lei de Diretrizes e Bases da Educação Nacional Lei número 9394, 20 de dezembro de 1996.

CEREJA, W. R.; MAGALHÃES, T. C. Português: Linguagens, Ensino Fundamental Língua portuguesa. Manual do professor. 9. ed. reformulada. São Paulo: Saraiva, 2015.

COSTA. N. M. Literaturas Afro-brasileira e Africanas: o desafio nos livros didáticos de Língua Portuguesa para o Ensino Médio. Dissertação (Mestrado em Ensino de Língua e Literatura), Universidade Federal do Tocantins, Araguaína - TO, 2014.

CRENSHAW, K. A interseccionalidade da discriminação de raça e gênero. 2002. Disponível em http://www.acaoeducativa.org.br/fdh/wp-content/uploads/2012/09/Kimberle-Crenshaw. pdf. Acesso em: 01 de maio de 2018.

FOUCAULT, M. A ordem do discurso. 5. ed. São Paulo: Loyola, 1996.

FIORIN, J. L. Linguagem e interdisciplinaridade. ALEA, v. 10, n. 1, jan-junho 2008, p. 29-53.

JUNIA, E. R. da S. Discursos sobre relações raciais em livros didáticos de português para as séries iniciais do ensino fundamental. Dissertação (Mestrado em Educação) - Universidade Federal de Minas Gerais, 2010.

MOITA LOPES, L. P. da. Identidades Fragmentadas. A construção discursiva de raça, gênero e sexualidade na sala de aula. Campinas, SP. Mercado de Letras, p. 551-561, 2002.

MORAES, M. C. O paradigma educacional emergente. São Paulo: Papirus, 1997.

NERI, A. L.; FREIRE, S. A. (Orgs.). E por falar em boa velhice. Campinas: Papirus, 2000.

PISCITELLI, A. Interseccionalidades, categorias de articulação e experiências de migrantes brasileiras. Sociedade e Cultura, v.11, n.2, jul/dez. 2008.

ROJO, R. H. R.; BATISTA, A. A. G. (Orgs.). Livro Didático de Língua Portuguesa, Letramento e Cultura da Escrita. 1. ed. Campinas: Mercado de Letras, 2003. v. 1. 320 p.

ROCHA, E. P. G. O que é etnocentrismo. 5. ed. São Paulo: Editora Brasiliense, 1988.

SILVA, T. T. da. Identidade e diferença: a perspectiva dos estudos culturais. Petrópolis, RJ: Vozes, 2000.

SILVA, T. T. da. A produção social da identidade e da diferença. In: SILVA, T. T. da. (Org.). Identidade e diferença: a perspectiva dos estudos culturais. Petrópolis: Vozes, 2009. 
SCOTT, P.; CORDEIRO, R. Violência, família e escola na busca de redes de apoio e direitos. In: SCOTT, P.; LEWIS, L; QUADROS, M. T. de. (Orgs.). Gênero, diversidade e desigualdades na Educação: interpretações e reflexões para a formação docente. Recife: Editora Universitária UFPE, 2009, p. 143-174.

SOUZA, S. dos S. O livro didático e as influências ideológicas das imagens: por uma educação que contemple a diversidade social e cultural. Dissertação (Mestrado em Educação, Sociedade e Culturas) - Universidade na Estadual de Feira de Santana, Feira de Santana, 2014.

WOODWARD, K. Identidade e diferença: uma introdução teórica e conceitual. In: SILVA, T. T. da (Org.). Identidade e diferença: a perspectiva dos estudos culturais. Petrópolis - RJ: Vozes, 2009.

Recebido para publicação em 30 de Dezembro de 2019. Aceito para publicação em 2 de Março de 2020. 